\title{
The role of total and cartilage-specific estrogen receptor alpha expression for the ameliorating effect of estrogen treatment on arthritis
}

\author{
Cecilia Engdahl 1,2*, Anna E Börjesson², Huamei F Forsman ${ }^{1}$, Annica Andersson ${ }^{1}$, Alexandra Stubelius ${ }^{1}$, \\ Andree Krust ${ }^{3}$, Pierre Chambon ${ }^{3}$, Ulrika Islander ${ }^{1}$, Claes OhIsson ${ }^{2}$, Hans Carlsten ${ }^{1}$ and Marie K Lagerquist ${ }^{1,2}$
}

\begin{abstract}
Introduction: Estrogen (E2) delays onset and decreases severity of experimental arthritis. The aim of this study was to investigate the importance of total estrogen receptor alpha (ERa) expression and cartilage-specific ERa expression in genetically modified mice for the ameliorating effect of estrogen treatment in experimental arthritis.

Methods: Mice with total (total ERa ${ }^{--}$) or cartilage-specific (Col2a1-ERa ${ }^{-/-}$) inactivation of ERa and wild-type (WT) littermates were ovariectomized, treated with E2 or placebo, and induced with antigen-induced arthritis (AIA). At termination, knees were collected for histology, synovial and splenic cells were investigated by using flow cytometry, and splenic cells were subjected to a T-cell proliferation assay.

Results: E2 decreased synovitis and joint destruction in WT mice. Amelioration of arthritis was associated with decreased frequencies of inflammatory cells in synovial tissue and decreased splenic T-cell proliferation. E2 did not affect synovitis or joint destruction in total $\mathrm{ERa}^{-/-}$mice. In Col2a1-ERa ${ }^{-/-}$mice, E2 protected against joint destruction to a similar extent as in WT mice. In contrast, E2 did not significantly ameliorate synovitis in Col2a1-ERa ${ }^{-/-}$mice.

Conclusions: Treatment with E2 ameliorates both synovitis and joint destruction in ovariectomized mice with AIA via ERa. This decreased severity in arthritis is associated with decreased synovial inflammatory cell frequencies and reduced splenic T-cell proliferation. ERa expression in cartilage is not required for estrogenic amelioration of joint destruction. However, our data indicate that ERa expression in cartilage is involved in estrogenic effects on synovitis, suggesting different mechanisms for the amelioration of joint destruction and synovitis by E2.
\end{abstract}

\section{Introduction}

Rheumatoid arthritis (RA) is an autoimmune disease characterized by a massive infiltration of mononuclear and polymorphonuclear cells into the joints and the development of inflammation that results in synovitis and destruction of articular cartilage and adjacent bone loss [1].

The mechanisms that give rise to RA are only partly understood, and several different immune cells, including lymphocytes, macrophages, and neutrophils, are involved.

\footnotetext{
* Correspondence: cecilia.engdahl@rheuma.gu.se

'Department of Rheumatology and Inflammation Research, Centre for Bone and Arthritis Research, Institute of Medicine, University of Gothenburg, Box 480, 40530 Gothenburg, Sweden

${ }^{2}$ Department of Internal Medicine and Clinical Nutrition, Centre for Bone and Arthritis Research, Institute of Medicine, University of Gothenburg, Vita Stråket 11, 41345 Gothenburg, Sweden

Full list of author information is available at the end of the article
}

Furthermore, a number of inflammatory mediators are implicated in the establishment and progression of arthritis, including proinflammatory cytokines such as tumor necrosis factor alpha (TNF $\alpha)$ and interleukin (IL) -6 and IL-17 $[2,3]$.

RA affects $0.5 \%$ to $1 \%$ of the population [4], and the female-to-male ratio is 3:1. Estrogen plays an important role in the pathogenesis of RA, and we and others have demonstrated, in different experimental arthritis models, that estrogen delays the onset and decreases the severity of the disease [5-8]. However, the role of estrogen in inflammatory diseases is complex $[9,10]$, and findings are contradictory; some human studies have reported no effect of estrogen, whereas we and others demonstrate beneficial effects of estrogen on RA [11-14]. Thus, there is a need to further understand the role of estrogen in RA. 
The physiological effects of estrogen are exerted mainly via the two classic nuclear estrogen receptors (ERs): $E R \alpha$ and ER $\beta$. Using ER-specific agonists, we have recently shown that the ameliorating effect of estrogen on collagen-induced arthritis is mediated mainly via $E R \alpha$ [5]. ER $\alpha$ is expressed in tissues adjacent to the joint inflammation, including cartilage and bone $[15,16]$, as well as in other peripheral tissues involved in the immune response, including thymus and spleen $[17,18]$. However, it is not known via which cell type estrogen mediates its ameliorating effect on arthritis.

Since long-term estrogen treatment to postmenopausal women is associated with severe side effects, knowledge about the mechanism behind the protective effects of estrogen is of considerable importance in the search for new treatment strategies for arthritis. In the present study, antigen-induced arthritis (AIA) was used to examine the influence of estrogen on arthritis. AIA shares many of the histological features of RA, such as leukocyte infiltration and synovitis together with bone and cartilage destruction [19], and is dependent on helper $\mathrm{T}$ cells, synovial macrophages, and neutrophils but independent of cytotoxic T cells and B cells [20-23].

To determine the importance of ER $\alpha$ for arthritis, we induced AIA in genetically modified mice lacking ER $\alpha$ expression in all cells. Furthermore, since estrogen can exert direct effects on cartilage via ER $\alpha$ [16], we used mice lacking ER $\alpha$ specifically in chondrocytes to determine the importance of local cartilage-specific ER $\alpha$ expression for the protective effects of estrogen on arthritis. By evaluating the estrogenic response in these two models, we determined the importance of (a) total ER $\alpha$ expression and (b) cartilage-specific ER $\alpha$ expression in arthritis amelioration.

We demonstrate that estrogen ameliorates AIA via ER $\alpha$. Furthermore, ER $\alpha$ expression in cartilage is not required for the amelioration of joint destruction. However, our data indicate that ER $\alpha$ expression in cartilage is involved in the ameliorating effects of estrogen on synovial inflammation.

\section{Materials and methods}

\section{Animals}

The ethics committee for animal experiments at the University of Gothenburg approved this study. Female mice were kept, 5 to 10 animals per cage, under standard environmental conditions and were fed with standard laboratory chow and tap water ad libitum.

In experiment 1 , female C57BL/6 wild-type (WT) (Scanbur NOVA-SCB AB, Sollentuna, Sweden) mice were used. In experiment 2, total ER $\alpha$ inactivated mice (total $\mathrm{ER \alpha}^{-1-}$ ) and WT littermates were used. Total $\mathrm{ER}^{-1-}$ mice have a deletion in exon 3 of the ER $\alpha$ gene and do not express any of the isoforms of the ER $\alpha$ protein.
The total $\mathrm{ER}^{-/-}$mice and corresponding WT $\left(\mathrm{ER}^{+/+}\right)$ littermates were inbred C57BL/6 mice and generated by breeding male $\mathrm{ER}^{+/-}$with female $\mathrm{ER}^{+/-}$mice, obtained as previously described [24]. In experiment 3 , cartilagespecific ER $\alpha$ inactivated mice and WT littermates were used. The generation of cartilage-specific ER $\alpha$ inactivated mice has previously been described, and these mice have a $62 \%$ reduction in ER $\alpha$ protein levels in cartilage but no reduction in bone or liver [25]. Briefly, mice in which exon 3 of the ER $\alpha$ gene is flanked by loxP sequences $\left(E R \alpha^{\text {flox/flox }}\right)$ were crossed with Col2 $\alpha 1$-Cre mice [26] to generate $\mathrm{Col} 2 \alpha 1-\mathrm{Cre} ; \mathrm{ER} \alpha^{\text {flox } /+}$ mice. These mice were crossed with $\mathrm{ER} \alpha^{\text {flox/flox }}$ mice to generate conditional mutants (Col2 $\alpha 1-\mathrm{Cre} ; \mathrm{ER}^{\text {flox/flox }}{ }^{\text {, hereafter }}$ referred to as Col2 $\alpha 1-\mathrm{ER \alpha}^{-/-}$) and corresponding littermate controls $\left(\mathrm{ER} \alpha^{\text {flox/flox }}\right)$. The $\mathrm{ER} \alpha^{\text {flox/flox }}$ mice are inbred C57BL/6 mice, and the Col2 $\alpha 1$-Cre mice were generated on a B6SJLF1 background and backcrossed more than six times with C57BL/6 mice.

\section{Ovariectomy and hormone treatment}

Total $\mathrm{ER}^{-1-}$ mice have increased sex steroid levels because of disturbed negative feedback regulation. To avoid confounding endogenous sex steroid effects and to imitate a postmenopausal state, all mice were ovariectomized and treated with placebo or estrogen. Ovariectomy (ovx) was performed at 10 weeks of age through a midline incision of the skin and flank incisions of the peritoneum. The skin incision was closed with metallic clips. Surgery was performed under anesthesia with isoflurane (Pfizer $A B$, Täby, Sweden). Carprofen (OrionPharma, Espoo, Finland) was used post-operatively as an analgesic.

Ovx mice were inserted with a subcutaneous slowrelease pellet (Innovative Research of America, Sarasota, FL, USA) with $17 \beta$-estradiol (E2) ( $0.83 \mu \mathrm{g} /$ day) or placebo. Mice treated with E2 in a dose similar to the one used in this study obtain serum E2 levels of approximately $60 \mathrm{pg} / \mathrm{mL}$ [27]. In mice, normal serum levels of E2 vary between 25 and $50 \mathrm{pg} / \mathrm{mL}$ in diestrus and between 150 and $200 \mathrm{pg} / \mathrm{mL}$ in estrus [28]. Thus, the dose used in this study resulted in physiological serum E2 levels. Treatment started at the time of ovx and lasted until termination.

\section{Induction of antigen-induced arthritis}

The mice were immunized with $0.2 \mathrm{mg}$ of methylated bovine serum albumin (mBSA) (Sigma-Aldrich, Stockholm, Sweden) dissolved in phosphate-buffered saline (PBS) and emulsified with an equal volume of complete Freund's adjuvant (Sigma-Aldrich). A total volume of $100 \mu \mathrm{L}$ was injected intradermally at the base of the tail $(50 \mu \mathrm{L}$ on each side). After 7 days, mice received an injection with $0.3 \mathrm{mg}$ of mBSA dissolved in $30 \mu \mathrm{L}$ of vehicle $\left(20 \% \mathrm{dH}_{2} \mathrm{O}\right.$ and $80 \%$ saline) into one knee joint. 


\section{Tissue collection and histological examination}

Fourteen days after the primary immunization, the mice were anaesthetized with Ketalar/Domitor (PfizerAB), bled, and killed by cervical dislocation. Serum was individually stored at $-20^{\circ} \mathrm{C}$ until use. Uteri were collected and weighed. The knees were separately placed in $4 \%$ formaldehyde, decalcified, and embedded in paraffin. Sections were stained with eosin/hematoxylin, and a blinded examiner (CE) graded synovitis and joint destruction. Synovial hypertrophy was defined as a membrane thickness of more than two cell layers [29]. A histological scoring system was used as follows: mild (1), moderate (2), and severe (3) synovitis and joint destruction. Bone erosions and cartilage degradation were considered separately in joint destruction.

\section{Single-cell preparation and cellularity measurement}

Spleens were harvested, and single-cell suspensions were obtained after the tissue was mashed and passed through a $70-\mu \mathrm{m}$ cell strainer (Becton Dickinson Biosciences Pharmingen, San Diego, CA, USA) in $15 \mathrm{~mL}$ of PBS. Pelleted cells from spleen were resuspended in Trisbuffered $0.83 \% \mathrm{NH}_{4} \mathrm{Cl}$ solution to lyse erythrocytes and washed in PBS. The total number of spleen leukocytes was analyzed in complete medium (Iscoves medium with L-glutamin, mercaptoethanol, gentamycin, and fetal calf serum) (Sigma-Aldrich) by using an automated cell counter (Sysmex, Hamburg, Germany). Synovial tissue was dissected and placed in medium (RPMI) (FisherScientific, Västra Frölunda, Sweden). Medium with DNaseI (SigmaAldrich) and collagenase type IV (Roche AB, Stockholm, Sweden) was added, and the suspension was incubated for 1 hour at $37^{\circ} \mathrm{C}$. A single-cell suspension was obtained after the tissue was mashed and passed through a $40-\mu \mathrm{m}$ cell strainer (Becton Dickinson) in $4 \mathrm{~mL}$ of PBS.

\section{Concanavalin A-induced T-cell proliferation in spleen cell cultures}

Isolated splenocytes from experiments 1 to 3 were suspended in complete medium $\left(1 \times 10^{6}\right.$ cells per $\left.\mathrm{mL}\right)$ and cultured in round-bottom plates (Nunc, Roskilde, Denmark) at $37^{\circ} \mathrm{C}, 5 \% \mathrm{CO}_{2}$, and $95 \%$ humidity. The Tcell mitogen concanavalin A (conA) (Sigma-Aldrich) was added to the medium in a final concentration of $1.25 \mu \mathrm{g} / \mathrm{mL}$, and cells with no added mitogen were used as controls. After 48 hours of culture, supernatants were taken from the wells. After an additional 2 hours (in total, 50 hours), $1 \mu \mathrm{Ci}[3 \mathrm{H}]$ thymidine (Amersham Pharmacia Biotech, Uppsala, Sweden) was added for 12 hours. Cells were harvested onto glass fiber filters and counted in a $\beta$-counter (PerkinElmer, Waltham, MA, USA). Cell cultures were set in triplicates, and results are presented as proliferation index (median of count per minute in wells with conA minus the median of count per minute in control wells).

\section{Cytokine analysis}

Cytokines from the conA-stimulated and control spleen cell culture supernatants were analyzed by using a Mouse Th1/Th2 10 plex FlowCytomix Multiplex kit (eBioscience, San Diego, CA, USA). The cytokine levels of control supernatants were subtracted from the conA-stimulated cytokine levels.

\section{Flow cytometry for analysis of cell phenotype}

Isolated splenocytes were stained for analysis by using the following antibodies: BD Horizon V450-conjugated anti-CD4 (Becton Dickinson) and fluorescein isothiocyanate (FITC)-conjugated anti-CD8 (Becton Dickinson). Synovial cells were examined by using BD Horizon V450-conjugated anti-CD11b (Becton Dickinson), FITCconjugated anti-CD3 (Becton Dickinson), allophycocyanin (APC)-conjugated anti-F4/80 (BioLegend, San Diego, CA, USA), Peridinin Chlorophyll Protein Complex (PerCP)conjugated anti-CD19 (BioLegend), and phycoerythrin (PE)-conjugated anti-Gr1. Labeled cells were analyzed in a FACS CantoII (Becton Dickinson). FlowJo version 8.5.2 (Tree Star, Ashland, OR, USA) software was used for analyzing the data.

\section{Measurement of mBSA antibodies}

Serum was analyzed for mBSA antibodies. IgG type Low bind Microplates (Nunc) were precoated with $0.1 \mathrm{~g} / \mathrm{mL}$ mBSA at $4^{\circ} \mathrm{C}$ overnight. After coating, the plates were washed, blocked with $2 \%$ casein, and incubated with the serum. Titration experiments were performed in order to find the optimal dilution of the sera for enzymelinked immunosorbent assay (ELISA) analysis. Biotinylated $\mathrm{F}\left(\mathrm{ab} \mathrm{b}^{\prime}\right) 2$ fragments of goat anti-mouse IgG (Jackson ImmunoResearch Laboratories, West Grove, PA, USA) were used as secondary antibody. Bound IgG was detected with a peroxidase-conjugated anti-mouse $\operatorname{IgG}$ (ICN Biochemicals, Aurora, OH, USA) and tetramethylbenzidine (Sigma-Aldrich) substrate. Absorbance was measured at $450 \mathrm{~nm}$ on a SpectraMax $340 \mathrm{DC}$ spectrophotometer (Molecular Devices, Sunnyvale, CA, USA).

\section{Real-time polymerase chain reaction}

RNA was isolated from the epiphyseal part of the femur, containing mainly articular and growth plate chondrocytes and trabecular bone, by using an RNeasy kit (Qiagen, Chatswort, CA, USA). Amplifications were performed by using the Applied Biosystem StepOnePlus ${ }^{\text {Th }}$ Real-Time PCR System (PE, Applied Biosystems, Stockholm, Sweden) and Assay-on-Demand primer and probe sets (PE, Applied Biosystems), labeled with reporter fluorescent dye FAM. Predesigned primers and probe labeled with reporter 
fluorescent dye VIC, specific for $18 \mathrm{~S}$ ribosomal RNA, were included in the reaction as an internal standard. The assay identification numbers were chemokine CXC motif ligand 1 (CXCL1): Mm04207460_m1 and chemokine CXC motif ligand 5 (CXCL5): Mm00436451_g1. The amount of mRNA was calculated by using a standard curve method in accordance with the instructions of the manufacturer (PE, Applied Biosystem) and adjusted for $18 \mathrm{~S}$ ribosomal RNA.

\section{Preparation of peritoneal exudate polymorphonuclear leukocytes}

Inflammation was induced by injecting $0.1 \mathrm{~mL}$ of uric acid solution (10\% uric acid in saline) into the peritoneal cavity of intact Col2 $\alpha 1-\mathrm{ER}^{-/-}$and WT littermates [30]. Before injection, the uric acid solution was sonicated for 10 minutes and shaken vigorously. Peritoneal exudate cells were harvested 4 hours after injection by lavages with cold PBS. Hypotonic lysis was performed after centrifugation ( $200 \mathrm{~g}$ for 10 minutes at $4^{\circ} \mathrm{C}$ ) to eliminate red blood cells, and the cells were washed in Krebs-Ringer glucose buffer. Nuclear staining using a Scepter ${ }^{\mathrm{rm}}$ (EMD Millipore, Billerica, MA, USA) determined the numbers of peritoneal exudate cells. The purity of the uric acid-induced peritoneal exudate cells was 95\% polymorphonuclear, and the remaining cell population was composed of mononuclear cells [30].

\section{Statistical analysis}

For statistical evaluation, Student $t$ tests were performed for comparison of two independent groups. The histological scoring was performed by using an ordinal scale system requiring non-parametric statistical evaluation and therefore the Mann-Whitney $U$ test was used.

\section{Results}

\section{Estrogen decreases antigen-induced arthritis severity}

Placebo- and E2-treated ovx mice (experiment 1, see Materials and methods) were challenged with antigen according to the regimen illustrated in Figure 1A. E2 treatment was confirmed by increased uterus weight compared with placebo $(740 \%, P<0.001)$. Placebo-treated ovx mice developed severe arthritis in the immunized knee joint, as revealed by massive cellular infiltration into the joint space, synovial inflammation, and joint destruction (Figure 1B,C). Histological examination of joints from E2-treated ovx mice showed significantly less joint destruction (bone erosions: $-37 \%, P<0.05$; cartilage degradation: $-62 \%, P<0.01)$ and synovial inflammation $(-21 \%, P<0.05)$ compared with placebo-treated mice, demonstrating that E2 treatment ameliorates disease severity in ovariectomized mice (Figure 1B,C).

Synovial cell populations were investigated by using flow cytometry. E2 treatment significantly decreased the frequency of neutrophils $(-49 \%, P<0.01)$ and monocytes/ macrophages $(-58 \%, P<0.01)$ compared with placebo treatment (Figure 1D,E). No significant effects were detected in lymphocyte frequencies (Figure 1F,G), although a tendency to decreased T-cell frequency $(-28 \%, P=0.051)$ was found (Figure 1F). Furthermore, the antigen-specific antibody response was investigated by measuring serum levels of mBSA-specific IgG, and similar levels were found in the placebo- and E2-treated animals (data not shown). These results suggest that neutrophils and monocytes/ macrophages are involved on a local level in the ameliorating effect of E2 on AIA.

Splenocytes from AIA-induced animals were investigated by using flow cytometry to determine the frequencies of $\mathrm{CD}^{+}{ }^{+}$helper $\mathrm{T}$ (Th) cells and $\mathrm{CD}^{+}$cytotoxic $\mathrm{T}$ (Tc) cells. There was a significant reduction in the frequency of $\mathrm{Th}$ cells $(-25 \%, P<0.05)$, but no effect on Tc cell frequency was seen after E2 treatment (Figure $1 \mathrm{H}$ ). These data are in accordance with the fact that AIA is dependent on Th, and not Tc, cells. Splenic proliferation was assessed after activation with the T-cell mitogen conA. E2 treatment decreased the proliferation $(-32 \%, P<0.05)$ compared with placebo treatment (Figure 1I). To further investigate the effect of E2 on the peripheral immune response, the cytokine profile was investigated in supernatants of conA-stimulated spleen cell cultures. The supernatants from E2-treated animals showed reduced levels of IL-17 (-51\%, $P<0.01)$, IL-2 (-27\%, $P<0.05)$, interferon-gamma $($ IFN- $\gamma)(-23 \%, P<0.05)$, and IL-6 $(-28 \%, P<0.05)$ versus placebo treatment, whereas levels of IL-4, TNF $\alpha$, and GMCSF (granulocyte macrophage colony-stimulating factor) were unchanged (Table 1), demonstrating that E2 treatment results in an altered systemic cytokine profile which may be important in the amelioration of arthritis.

\section{Estrogen ameliorates antigen-induced arthritis via ERa}

We have previously shown that ER $\alpha$ is important for the ameliorating effects of estrogen in collagen-induced arthritis and immune-mediated bone loss, using estrogen receptor-specific agonists [5]. To confirm the requirement of ER $\alpha$ for the ameliorating effects of E2 treatment on arthritis by using a genetically modified animal model, total $\mathrm{ER}^{-/-}$and their corresponding WT littermates (experiment 2, see Materials and methods) were challenged with antigen according to the regimen illustrated in Figure 1A. E2 treatment significantly increased the uterus weight of WT littermates $(805 \%, P<0.001)$, but not total $\mathrm{ER}^{-1-}$ mice, compared with placebo. There were no significant differences between placebo-treated WT and total $\mathrm{ER}^{-/-}$mice regarding synovitis or joint destruction, demonstrating that unliganded ER $\alpha$ is not involved in the development of AIA. As expected, histological examination of placebo-treated joints in WT littermates revealed severe arthritis in the immunized knee joints and E2 


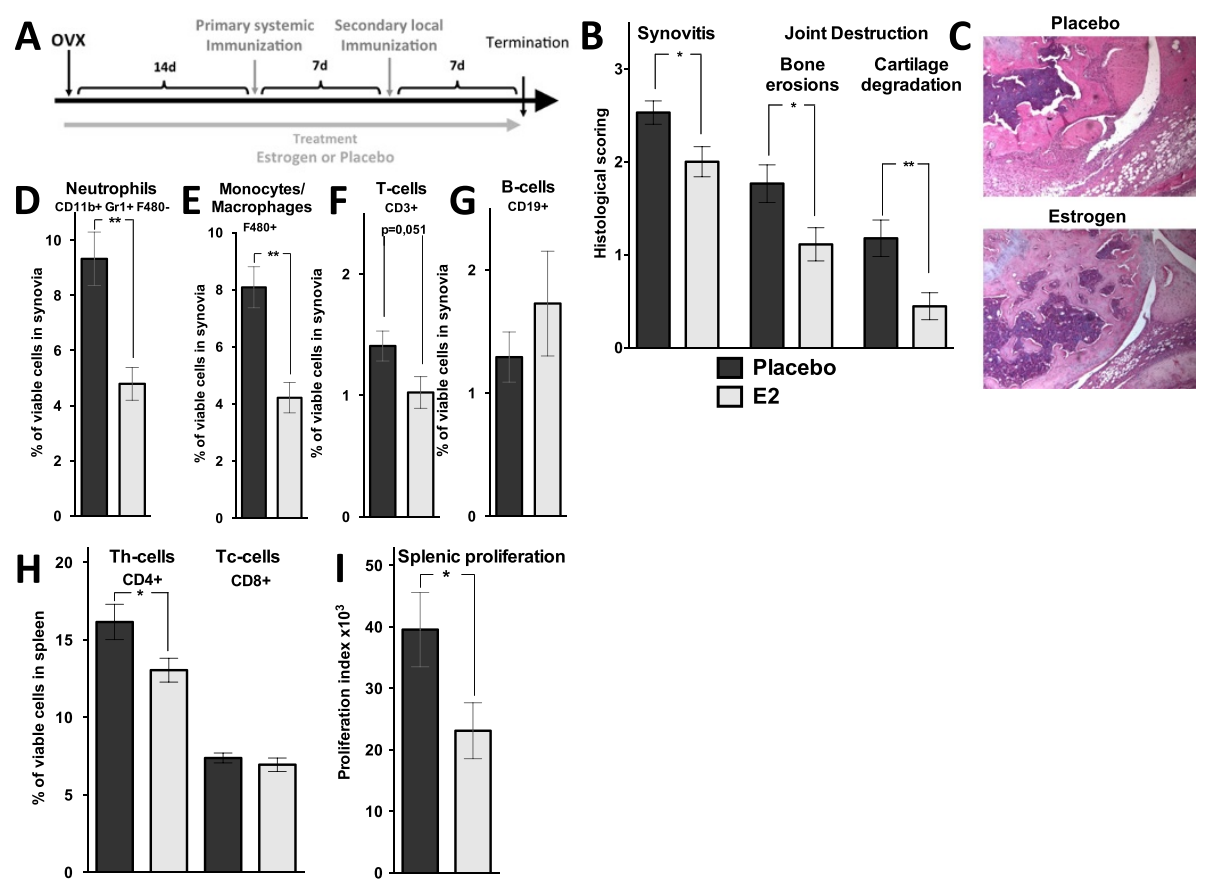

Figure 1 Estrogen ameliorates antigen-induced arthritis (AIA). (A) Scheme for AIA. Total ERa ${ }^{-1-}$, Col2a1-ERa ${ }^{-/-}$, and wild-type (WT) mice were ovariectomized $(\mathrm{OVX})$ at 10 weeks of age, followed by insertion of slow-release treatment pellets with placebo or estrogen (E2) (0.83 $\mu \mathrm{g} / \mathrm{day})$. Fourteen days after ovariectomy, the animals were immunized by an intradermal injection of methylated bovine serum (mBSA) emulsified in Freund's complete adjuvant (0.2 mg mBSA) and 7 days later given an intra-articular (IA) injection of mBSA (0.3 mg mBSA dissolved in 30 $\mu \mathrm{L}$ of vehicle) in one knee joint. Seven days after the IA injection, the mice were bled and terminated. (B) Knee joints obtained at termination of WT mice with AIA treated with placebo or estrogen were examined with a histological scoring of synovitis and joint destruction. The histological examination was performed by using a scale from 1 to $3: 1$, mild; 2 , moderate; and 3, severe. ${ }^{*} P<0.05$, ${ }^{* *} P<0.01$, Mann-Whitney $U$ test. $(n=17-18)$. (C) Representative images of joint histology. Percentage of viable (D) neutrophils $\left(\mathrm{CD} 11 \mathrm{~b}^{+}, \mathrm{Gr}^{+}, \mathrm{F} 480^{-}\right)$, (E) monocytes/macrophages $\left(\mathrm{F} 480^{+}\right)$, (F) T cells $\left(\mathrm{CD} 3^{+}\right)$, and $(\mathbf{G}) B$ cells $\left(\mathrm{CD} 19^{+}\right)$ in synovia tissues. ${ }^{*} P<0.05$, Student $t$ test $(n=7-8)$. (H) Percentage of viable $C D 4^{+}$Th (T helper) cells and CD8 ${ }^{+} T c$ (T cytotoxic) cells in the spleen. ${ }^{*} P<0.05$, Student $t$ test. $(n=17-18$ ). (I) Proliferation of splenocytes after stimulation with the T-cell mitogen concanavalin $A$ (conA). Cell cultures were set in triplicates, and results are presented as proliferation index (median of count per minute in wells with conA minus the median of count per minute in control wells). ${ }^{*} P<0.05$, Student $t$ test $(n=17-18)$. Results are shown as mean \pm standard error of the mean.

treatment reduced joint destruction (bone erosions: $-45 \%$, $P<0.01$; cartilage degradation: $-73 \%, P<0.001)$ as well as synovial inflammation $(-20 \%, P<0.01)$ (Figure $2 \mathrm{~A}, \mathrm{~B})$. In contrast, E2 treatment did not ameliorate synovitis or joint destruction in total $\mathrm{ER}^{-/-}$animals (Figure 2A,B). This finding demonstrates that ER $\alpha$ is required for the ameliorating effect of E2 in AIA.

Splenocytes from total $\mathrm{ER}{ }^{-/-}$mice and WT littermates were investigated by using flow cytometry. E2 reduced the frequency of Th cells, but not Tc cells, in WT mice $(-28 \%, P<0.01)$, whereas no estrogenic effect was detected in total $\mathrm{ER \alpha}^{-1-}$ animals (Figure 2C). Proliferation was assessed in splenocytes after activation with the T-cell mitogen conA. As expected, E2 reduced the proliferation $(-50 \%, P<0.01)$ compared with placebo treatment in WT littermates, whereas no estrogenic effect was detected in total $\mathrm{ER \alpha}^{-/-}$animals compared with placebo (Figure 2D). The cytokine profile in supernatants of the proliferation cultures showed significantly reduced levels of IL-17 $(-71 \%, P<0.01)$ and IFN- $\gamma(-68 \%, P<0.05)$ and tendencies to reduced levels of IL-2 $(-38 \%, P=0.075)$ and IL-6
$(-36 \%, P=0.06)$ in WT littermates after E2 treatment compared with placebo treatment (Table 1). In contrast, E2 did not influence the cytokine pattern in total $E R \alpha^{-/-}$ animals. These results demonstrate that $E R \alpha$ is required for the reduced frequency of systemic Th cells, the reduced T-cell proliferation, and the altered cytokine profile seen after E2 treatment.

\section{ERa in cartilage is not required for the ameliorating} effects of estrogen on joint destruction but is involved in the ameliorating effects of estrogen on synovial inflammation

Chondrocytes express ER $\alpha$, and estrogen can exert direct effects on these cells [16]. Expression of ER $\alpha$ in cartilage therefore may be involved in the ameliorating effect of estrogens on AIA. Col2 $\alpha 1-\mathrm{ER}^{-1-}$ mice, lacking ER $\alpha$ expression specifically in chondrocytes, and their corresponding WT littermates (experiment 3, see Materials and methods) were challenged with antigen according to the regimen illustrated in Figure 1A. Treatment with E2 significantly induced the uteri weight compared with 


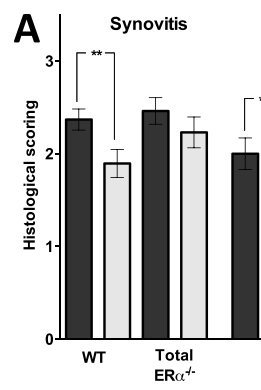

Joint Destruction Bone
erosions \begin{tabular}{ll}
$\Gamma^{*}$ & $\square$ Placebo \\
\hline E2
\end{tabular}
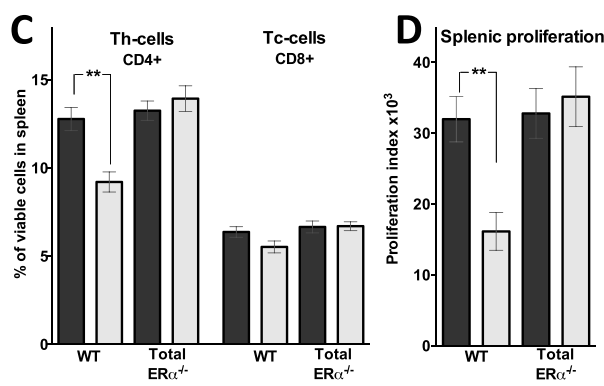
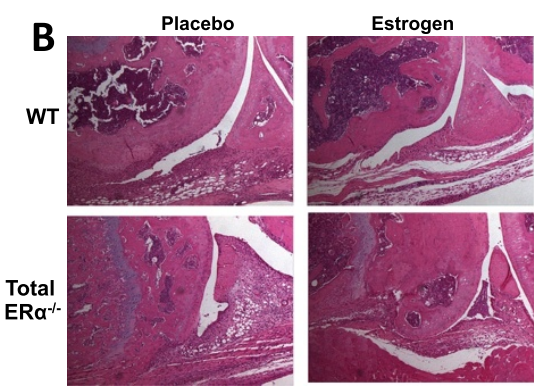

Figure 2 Estrogen ameliorates antigen-induced arthritis (AIA) via estrogen receptor alpha (ERa). Total ERa ${ }^{-1-}$ and wild-type (WT) littermates were treated with placebo or estrogen (E2) $(0.83 \mu \mathrm{g} /$ day) and induced with AIA. (A) Histological scoring of synovitis and joint destruction. The histological examination was performed by using a scale from 1 to $3: 1$, mild; 2 , moderate; and 3, severe. ${ }^{*} P<0.05,{ }^{* *} P<0.01$, ${ }^{* * *} P<0.001$ Mann-Whitney $U$ test. (B) Representative images of joint histology. (C) Percentage of viable CD4 ${ }^{+}$Th ( $T$ helper) cells and CD ${ }^{+} T c$ (T cytotoxic) cells in the spleen. ${ }^{* *} P<0.01$, Student $t$ test. (D) In vitro proliferation of splenocytes, harvested from mice with AlA treated with placebo or E2 $(0.83 \mathrm{\mu g} /$ day), after stimulation with the T-cell mitogen concanavalin A (conA). Cell cultures were set in triplicates, and results are presented as proliferation index (median of count per minute in wells with conA minus the median of count per minute in control wells). ${ }^{*} P<0.05$, Student $t$ test. Results are shown as mean \pm standard error of the mean $(n=14-19)$.

Table 1 Cytokines in supernatants from spleen cell proliferation cultures

\begin{tabular}{|c|c|c|c|c|c|c|}
\hline \multirow[b]{2}{*}{$(\mathrm{pg} / \mathrm{mL})$} & & \multirow{2}{*}{$\begin{array}{c}\text { (Exp. 1) } \\
\text { WT }\end{array}$} & \multicolumn{2}{|c|}{ (Exp. 2) Total ERa ${ }^{-/-}$} & \multicolumn{2}{|c|}{ (Exp. 3) Col2a1-ERa ${ }^{-1-}$} \\
\hline & & & WT & KO & WT & KO \\
\hline \multirow[t]{2}{*}{ IL-17 } & $P$ & $850 \pm 107$ & $158 \pm 33$ & $97 \pm 23$ & $785 \pm 158$ & $715 \pm 124$ \\
\hline & E2 & $417 \pm 80^{\mathrm{a}}$ & $46 \pm 18^{\mathrm{a}}$ & $130 \pm 41$ & $391 \pm 79^{b}$ & $335 \pm 103^{b}$ \\
\hline \multirow[t]{2}{*}{ IFNY } & $\mathbf{P}$ & $1,039 \pm 69$ & $8,881 \pm 2,865$ & $7,294 \pm 3,192$ & $4,465 \pm 1,070$ & $4,782 \pm 760$ \\
\hline & E2 & $800 \pm 54^{b}$ & $2,813 \pm 528^{b}$ & $4,926 \pm 694$ & $1,622 \pm 360^{b}$ & $2,697 \pm 340^{b}$ \\
\hline \multirow[t]{2}{*}{ IL-2 } & $\mathbf{P}$ & $1,038 \pm 83$ & $4,355 \pm 581$ & $4,098 \pm 540$ & $7,128 \pm 1,598$ & $4,405 \pm 1,085$ \\
\hline & E2 & $759 \pm 64^{b}$ & $2,697 \pm 663^{c}$ & $3,120 \pm 640$ & $1,247 \pm 403^{b}$ & $531 \pm 134^{b}$ \\
\hline \multirow[t]{2}{*}{ IL-6 } & $\mathbf{P}$ & $644 \pm 48$ & $596 \pm 85$ & $475 \pm 127$ & $523 \pm 81$ & $425 \pm 59$ \\
\hline & E2 & $469 \pm 59^{b}$ & $383 \pm 66^{d}$ & $447 \pm 57$ & $326 \pm 68$ & $227 \pm 56^{\mathrm{b}}$ \\
\hline \multirow[t]{2}{*}{ IL-4 } & $\mathbf{P}$ & $337 \pm 80$ & $114 \pm 12$ & $95 \pm 9$ & $120 \pm 38$ & $122 \pm 48$ \\
\hline & E2 & $279 \pm 41$ & $90 \pm 9$ & $102 \pm 12$ & $141 \pm 30$ & $102 \pm 62$ \\
\hline \multirow[t]{2}{*}{ TNFa } & $\mathbf{P}$ & $147 \pm 27$ & $95 \pm 18$ & $105 \pm 15$ & $169 \pm 32$ & $125 \pm 15$ \\
\hline & E2 & $190 \pm 73$ & $109 \pm 31$ & $94 \pm 15$ & $122 \pm 20$ & $88 \pm 22$ \\
\hline \multirow[t]{2}{*}{ GM-CSF } & $P$ & $195 \pm 22$ & $877 \pm 268$ & $1,011 \pm 202$ & $430 \pm 162$ & $719 \pm 361$ \\
\hline & E2 & $158 \pm 123$ & $1,118 \pm 246$ & $826 \pm 152$ & $472 \pm 189$ & $1,069 \pm 229$ \\
\hline
\end{tabular}

The cytokine profile was investigated in supernatants of concanavalin A-stimulated spleen cell cultures from experiments $1(n=9-10), 2(n=12-17)$, and $3(n=8-11)$ (see Materials and methods). Values are given as mean \pm standard error of the mean. ${ }^{\mathrm{a}} P<0.01,{ }^{\mathrm{b}} P<0.05$ versus placebo, Student $t$ test, ${ }^{\mathrm{c}} P=0.075$, ${ }^{\mathrm{d}} P=0.06$. E2, estrogen; Exp., experiment; IFNy, interferon gamma; IL, interleukin; KO, knockout; $\mathrm{P}$, placebo; GM-CSF, granulocyte macrophage colony-stimulating factor; TNFa, tumor necrosis factor alpha; WT, wild-type. 
placebo in both WT $(938 \%, P<0.001)$ and Col2 $\alpha 1$ $\mathrm{ER}^{-1-}(724 \%, P<0.001)$ mice. As seen for total $\mathrm{ER}^{-/-}$ animals, there were no significant differences between placebo-treated WT and Col2 $\alpha 1-\mathrm{ER}^{-/-}$mice regarding synovitis or joint destruction, demonstrating that unliganded ER $\alpha$ in chondrocytes is not involved in the development of AIA. E2 treatment of both WT and $\mathrm{Col} 2 \alpha 1-\mathrm{ER}^{-/-}$mice decreased bone erosions $(-63 \%$ and $-59 \%$, respectively; $P<0.01)$ and cartilage degradation (-66\% and $-74 \%$, respectively; $P<0.05$ ) (Figure $3 \mathrm{~A}, \mathrm{~B}$ ). Interestingly, E2 decreased synovitis in WT mice $(-28 \%$, $P<0.05)$ but had no significant effect on synovitis in $\mathrm{Col} 2 \alpha 1-\mathrm{ER}^{-/-}$animals (Figure 3A,B). These results suggest that ER $\alpha$ expression in cartilage is involved in the protective effects of E2 on synovial inflammation but that ER $\alpha$ in cartilage is dispensable for the effect of E2 on joint destruction. These results were repeated in an additional experiment $(\mathrm{n}=11-13)$ with similar results (data not shown).
Flow cytometry analysis of splenocytes demonstrated reduced Th cell frequency after E2 treatment in both WT $(-21 \%, P<0.05)$ and Col2 $\alpha 1-\mathrm{ER}^{-/-}(-17 \%, P<0.05)$ mice, whereas Tc cells were not affected by E2 treatment (Figure 3G). E2 decreased the proliferative response in splenocytes after conA stimulation in WT littermates $(-45 \%, P<0.05)$ compared with placebo, and there was a tendency of decreased proliferative response also in the Col2 $\alpha 1-\mathrm{ER}^{-1-}$ mice $(-33 \%, P=0.06)$ (Figure 3H). Furthermore, E2 affected the cytokine profile in supernatants of the spleen cell proliferation cultures similarly in WT and Col2 $\alpha 1-\mathrm{ER}^{-/-}$mice with reduced levels of IL-2, IL-17, and IFN- $\gamma$ (Table 1). Thus, ER $\alpha$ expression in cartilage does not influence the systemic immune response to E2 in AIA.

Synovial cells were investigated by using flow cytometry, and E2 treatment reduced the monocyte/macrophage frequency in Col2 $\alpha 1-\mathrm{ER}^{-/-}$mice compared with placebo $(-50 \%, P<0.05)$, and there was a tendency to decrease in WT mice compared with placebo $(-36 \%, P=0.07)$

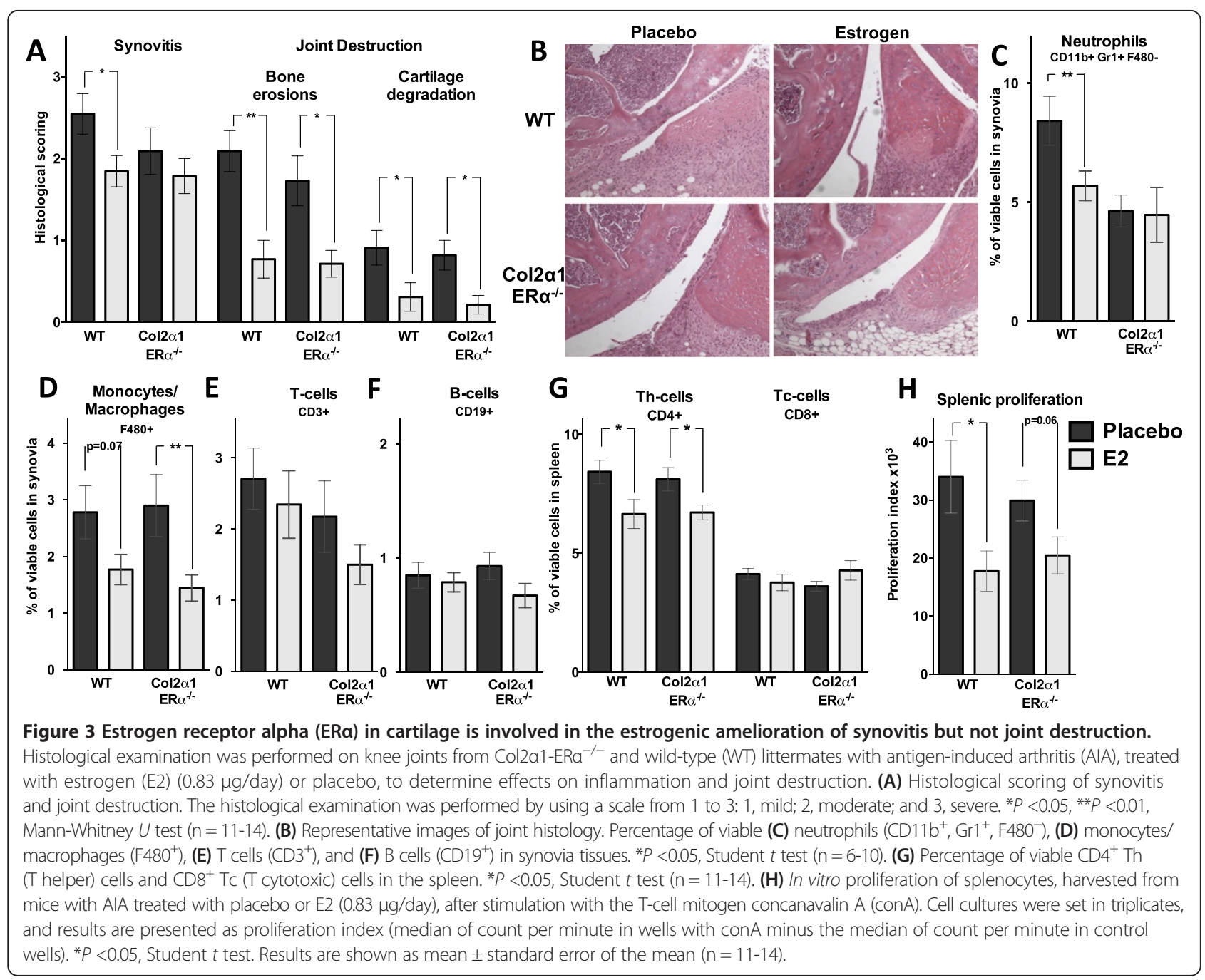


(Figure 3D). No effects were detected in lymphocyte frequencies (Figure 3E,F). However, E2 treatment decreased the neutrophil frequency in WT mice compared with placebo $(-32 \%, P<0.05)$, whereas no E2 effect on neutrophils was detected in Col2 $\alpha 1-E R \alpha^{-1-}$ mice compared with placebo (Figure 3C). A comparison between the placebotreated mice showed that the frequency of neutrophils was significantly decreased in Col $2 \alpha 1-\mathrm{ER}^{-/-}$mice compared with WT littermates $(-45 \%, P<0.05)$. To investigate the cause of the decreased neutrophil frequency in the synovia in Col $2 \alpha 1-\mathrm{ER}^{-/-}$mice, we analyzed the expression of neutrophil chemoattractants. Expression of the neutrophil chemoattractants CXCL1 and CXCL5 was investigated in the epiphyseal part of the femur, close to the arthritic joint. E2 treatment did not affect CXCL1 or CXCL5 expression in either WT or Col2 $\alpha 1$-ER $\alpha^{-/-}$ mice (Figure 4A,B). However, the CXCL1 expression was significantly decreased in Col $2 \alpha 1-\mathrm{ER}^{-/-}$mice compared with WT littermates both after placebo treatment $(-72 \%, P<0.05)$ and after E2 treatment $(-57 \%, P<0.05)$ (Figure 4A).

The systemic neutrophil migration capability was investigated in Col2 $\alpha 1-\mathrm{ER}^{-/-}$mice and WT littermates by inducing peritoneal inflammation and investigating the number of neutrophils in the peritoneal exudate. The neutrophil count was equal between WT and Col2 $\alpha 1-\mathrm{ER}^{-/-}$mice (Figure $4 \mathrm{C}$ ), suggesting that there is no difference in the systemic neutrophil responsiveness in mice lacking $\mathrm{ER} \alpha$ expression specifically in chondrocytes compared with WT littermates.

\section{Discussion}

RA is an autoimmune disease characterized by chronic inflammation, which leads to destruction of cartilage and bone loss. Several studies have shown that estrogen exerts positive effects on arthritis and arthritis-related immunemediated bone loss $[13,14]$, but owing to negative side effects, estrogen is not considered suitable as a long-term treatment. It is therefore of importance to determine the mechanism behind its protective effects on arthritis in order to develop new treatment strategies which retain the positive, but not the negative, effects of estrogen. We demonstrate that estrogen (E2) treatment ameliorates both synovitis and joint destruction in AIA via ER $\alpha$ and that ER $\alpha$ expression in cartilage cells is dispensable for the estrogenic protection against joint destruction. Interestingly, our data indicate that ER $\alpha$ expression in cartilage is involved in the estrogenic effects on synovitis.

Estrogen signaling is complex, involving two classic nuclear receptors: ER $\alpha$ and ER $\beta$. We and others have previously reported that activation of $E R \alpha$, using selective $E R \alpha$ agonists, decreases the severity of both collageninduced arthritis and AIA [5,31,32]. In the present study, we have used genetically modified mouse models, which are on a genetic background rendering them relatively insensitive to collagen-induced arthritis, and therefore we have used AIA as a model of arthritis in order to effectively assess effects on arthritis severity. We show that total deletion of ER $\alpha$ expression inhibits the protective effects of E2 on both synovitis and joint destruction, demonstrating the crucial role of ER $\alpha$ for the ameliorating effect of estrogen on arthritis in female mice. ER $\beta$ activation has also been implicated to play a role in the amelioration of arthritis in males [32,33]. However, we and others have shown, in both female and male rodents, that ER $\alpha$, and not ER $\beta$, activation ameliorates arthritis [5,31]. Furthermore, in the present study, E2 treatment was not able to ameliorate arthritis in ER $\alpha$ inactivated mice despite the presence of
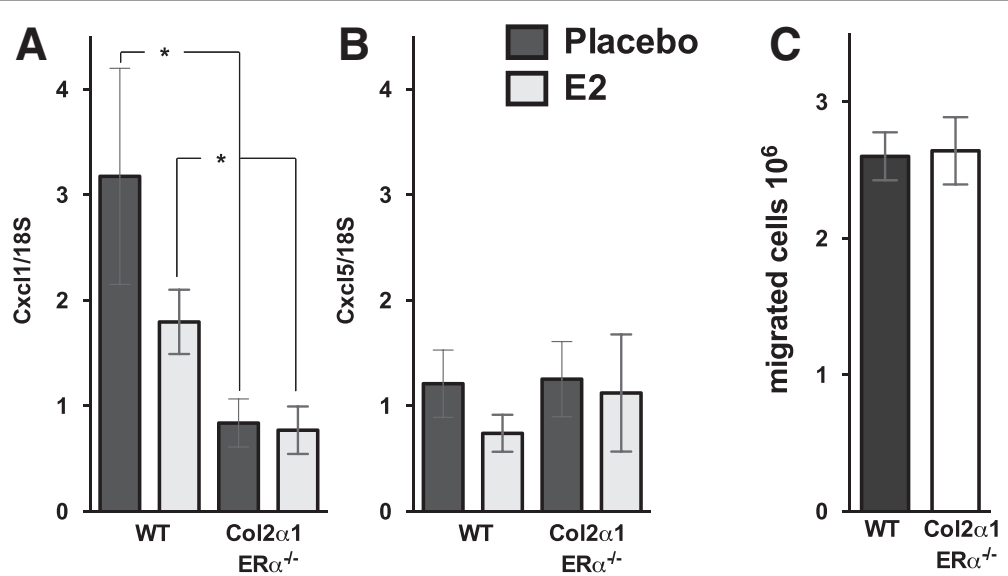

Figure 4 Estrogen receptor alpha (ERa) expression in cartilage affects local gene expression of the neutrophil chemokine CXCL1 but has no effect on systemic neutrophil migration capacity. Col2a1-ERa ${ }^{-/-}$and wild-type (WT) littermates were treated with placebo or estrogen (E2) $(0.83 \mathrm{\mu g} / \mathrm{day})$ and induced with antigen-induced arthritis. Expression of (A) Cxcl1 and (B) Cxcl5 in the epiphyseal part of the femur. The mRNA level of each gene was adjusted for expression of $18 \mathrm{~S}$ rRNA. (C) Neutrophil migration was evaluated by analysis of the number of peritoneal exudate cells after induction of inflammation in the peritoneal cavity by using uric acid. ${ }^{*}<<0.05$, Student $t$ test. Results are shown as mean \pm standard error of the mean $(n=4-8)$. 
$E R \beta$, demonstrating that ER $\alpha$ is the main receptor mediating the protective effects of estrogen on arthritis.

$\mathrm{T}$ cells are of particular importance in AIA and this is supported by the fact that nude mice lacking $\mathrm{T}$ cells cannot be induced with AIA [22]. Estrogen affects T lymphopoiesis, and we and others have previously demonstrated that estrogenic repression of $\mathrm{T}$ lymphopoiesis is mediated via ER $\alpha$ [27,34]. Estrogen has also been shown to decrease systemic T lymphocyte proliferation [35], and herein we confirm these results and establish that expression of ER $\alpha$ is required for the decreased conA-stimulated splenic Tcell proliferation. In this study, we demonstrate that E2 decreases the frequency of splenic Th cells via ER $\alpha$, whereas Tc cells are unaffected. These results are in accordance with the notion that AIA is a Th-dependent disease [22]. Our study shows a clear estrogenic effect on systemic Th cells found in the spleen, whereas the local $\mathrm{T}$ cells, in the inflamed synovial membrane, are not significantly affected. It has previously been reported that systemic, rather than local, counteraction of Th cell function is responsible for the beneficial effects of Th cell depletion in the AIA model [36], and we suggest that systemic, rather than local, effects on Th cells are involved in the therapeutic efficiency of E2 in AIA. Evaluation of the cytokines produced by splenocytes treated with the Tcell mitogen conA demonstrated that E2 treatment reduces the levels of IFN- $\gamma$, IL-2, IL-6, and IL-17 and that this reduction is mediated via $E R \alpha$. These cytokines are all implicated in the pathogenesis of arthritis [37,38] and may be involved in the ameliorating effect of estrogen on arthritis. AIA is not dependent on B cells, except in very severe cases [23]. Accordingly, we found that neither antigen-specific antibodies nor the B-cell frequency in synovia was associated with the estrogenic amelioration of arthritis.

The role of chondrocytes in the pathogenesis of arthritis has gained increasing interest. The recent finding that synovial fluid from patients with RA triggers secretion of various cytokines from chondrocytes, including cytokines involved in chemotactic migration of immune cells, suggests that these cells can actively take part in inflammatory joint diseases and not just be passive participators, as previously believed $[39,40]$. Chondrocytes express ERs, and estrogen can affect protein production in these cells [16]. We have recently shown that ER $\alpha$ expression in cartilage is important for the reduction of growth plate height induced by high E2 levels in adult mice, using a cartilage-specific ER $\alpha$ inactivated mouse model (Col2 $\alpha 1-\mathrm{ER}^{--l}$ mice) [25]. In this study, we used the Col2 $\alpha 1-\mathrm{ER}^{-/-}$mice to determine the importance of cartilage-specific ER $\alpha$ expression for the ameliorating effects of estrogen on arthritis. E2 treatment of Col2 $\alpha 1-$ $\mathrm{ER}^{-/-}$mice resulted in a similar reduction in joint destruction as seen in WT littermates, demonstrating that
$E R \alpha$ expression in chondrocytes is not involved in the estrogenic protection against joint destruction. Interestingly, E2 treatment did not significantly reduce the synovial inflammation in mice lacking ER $\alpha$ expression in chondrocytes, suggesting different target cells and mechanisms for the estrogenic protection against synovial inflammation and joint destruction. Dissociation between synovial inflammation and joint destruction has been described before where treatments have provided protection against bone erosions despite continuous synovial inflammation [41], and progression of bone erosions has been detected despite improvement of inflammatory scores [42]. In an attempt to understand the mechanism behind the lack of estrogenic response on synovial inflammation in Col2 $\alpha 1-\mathrm{ER}^{-/-}$mice, we examined synovial cell populations. Synovial monocytes/macrophages and neutrophils are known to be important in RA and produce cytokines and chemokines that attract and further activate the immune system [43,44], and estrogen regulates both the number and function of neutrophils as well as reduces neutrophil chemotaxis [45]. We show that E2 treatment reduced the frequency of monocytes/macrophages in the joints both in WT littermates and in Col $2 \alpha 1-\mathrm{ER}^{-1-}$ mice. In contrast, E2 treatment was only able to decrease the frequency of neutrophils in the joints of WT littermates, whereas the neutrophils were unaffected by E2 treatment in mice lacking ER $\alpha$ expression in chondrocytes. Thus, the inability of E2 to significantly decrease synovitis in mice lacking ER $\alpha$ expression in cartilage cells may depend on the lack of E2 effect on neutrophils. The lack of E2 effect on neutrophils might be influenced by the fact that the number of neutrophils in the placebo-treated cartilage-specific ER $\alpha$ inactivated mice compared with the placebo-treated WT mice was significantly lower, suggesting that ER $\alpha$ expression in cartilage might be involved in the migration of neutrophils. Accordingly, we found that expression of the neutrophil chemokine CXCL1 [46,47], known to be expressed in chondrocytes $[48,49]$, was decreased in the $\mathrm{Col} 2 \alpha 1-\mathrm{ER}^{-/-}$mice, whereas no significant difference was detected in the expression of the neutrophil chemokine CXCL5, known to be expressed in cells of the myeloid lineage, including monocytes and osteoclasts [50]. Our data indicate that $\mathrm{ER} \alpha$ expression in chondrocytes is required for normal expression of CXCL1 and thus for normal local migration of neutrophils into the joint. In addition, we found no differences in the systemic neutrophil responsiveness in the Col2 $\alpha 1-\mathrm{ER}^{-1-}$ mice, which indicates that only the local migration of neutrophils into the arthritic joint is altered in the Col2 $\alpha 1-\mathrm{ER}^{-/-}$mice.

\section{Conclusions}

$E R \alpha$ is required for the protective effects of estrogen treatment of AIA in ovx animals. Furthermore, ER $\alpha$ expression 
in cartilage is not required for the estrogenic amelioration of joint destruction. However, our data indicate that $\mathrm{ER} \alpha$ expression in cartilage is involved in estrogenic effects on synovitis by influencing neutrophil migration, suggesting different mechanisms for the amelioration of joint destruction and synovitis by E2. Increased knowledge about the mechanisms behind the beneficial effects of estrogen is useful in the search for novel treatments against arthritis.

\section{Abbreviations}

AIA: antigen-induced arthritis; conA: Concanavalin A; E2: estrogen; ER: estrogen receptor; FITC: fluorescein isothiocyanate; IFN-ү: interferon-gamma; IL: interleukin; mBSA: methylated bovine serum albumin; ovx: ovariectomy; PBS: phosphate-buffered saline; RA: rheumatoid arthritis; Tc: $C D 8^{+}$cytotoxic T cell; Th: CD4 ${ }^{+}$helper T cell; TNFa: tumor necrosis factor alpha; WT: wild-type.

\section{Competing interests}

The authors declare that they have no competing interests.

\section{Authors' contributions}

All authors made substantial contributions to the conception of the experiments and were involved in drafting the manuscript and revising it critically for important intellectual content. CE was involved in the design of the study and performed the AIA induction, histological examination, T-cell proliferation, flow cytometry, measurements of mBSA antibodies, and the statistical analyses. PC, AK, CO, and HC were involved in the design of the study. $\mathrm{ML}$ was involved in the design of the study and performed the ovariectomies, tissue collection, and statistical analyses. AB performed the breeding, genotyping, ovariectomies, tissue collections, and single-cell preparations. HF performed neutrophil assay, tissue collection, and single-cell preparation. $\mathrm{AA}, \mathrm{AS}$, and UI performed tissue collection, single-cell preparation, cellularity measurements, cytokine analysis, and flow cytometry. All authors read and approved the final manuscript.

\section{Acknowledgments}

We thank Malin Erlandsson and Maud Petersson for excellent technical assistance. This work was supported by the Medical Faculty of University of Gothenburg, the Göteborg Medical Society, the Rheuma Research fund Margareta, COMBINE, the Swedish Research Council, King Gustav V's 80 years' foundation, the Association against Rheumatism, the Swedish Association for Medical Research, LUA/ALF, the Åke Wiberg foundation, and the Ragnar Söderberg foundation.

\section{Author details}

'Department of Rheumatology and Inflammation Research, Centre for Bone and Arthritis Research, Institute of Medicine, University of Gothenburg, Box 480, 40530 Gothenburg, Sweden. ${ }^{2}$ Department of Internal Medicine and Clinical Nutrition, Centre for Bone and Arthritis Research, Institute of Medicine, University of Gothenburg, Vita Stråket 11, 41345 Gothenburg, Sweden. ${ }^{3}$ Department of Functional Genomics, IGBMC, Collège de France, B. P. 10142, 67404 Illkirch, France.

Received: 5 July 2012 Accepted: 1 July 2014

Published: 15 July 2014

\section{References}

1. Feldmann M, Brennan FM, Maini RN: Rheumatoid arthritis. Cell 1996, 85:307-310.

2. Maldonado CA, Castagna LF, Rabinovich GA, Landa CA: Immunocytochemical study of the distribution of a 16-kDa galectin in the chicken retina. Invest Ophthalmol Vis Sci 1999, 40:2971-2977.

3. Egan PJ, van Nieuwenhuiize A, Campbell IK, Wicks IP: Promotion of the local differentiation of murine Th17 cells by synovial macrophages during acute inflammatory arthritis. Arthritis Rheum 2008, 58:3720-3729.

4. Doran MF, Pond GR, Crowson CS, O'Fallon WM, Gabriel SE: Trends in incidence and mortality in rheumatoid arthritis in Rochester, Minnesota, over a forty-year period. Arthritis Rheum 2002, 46:625-631.

5. Engdahl C, Jochems C, Windahl SH, Borjesson AE, Ohlsson C, Carlsten H, Lagerquist MK: Amelioration of collagen-induced arthritis and immune- associated bone loss through signaling via estrogen receptor alpha, and not estrogen receptor beta or $\mathrm{G}$ protein-coupled receptor 30. Arthritis Rheum 2010, 62:524-533.

6. Jochems C, Islander U, Kallkopf A, Lagerquist M, Ohlsson C, Carlsten H: Role of raloxifene as a potent inhibitor of experimental postmenopausal polyarthritis and osteoporosis. Arthritis Rheum 2007, 56:3261-3270.

7. Holmdahl R, Jansson L, Andersson M: Female sex hormones suppress development of collagen-induced arthritis in mice. Arthritis Rheum 1986, 29:1501-1509.

8. Yamasaki D, Enokida M, Okano T, Hagino H, Teshima R: Effects of ovariectomy and estrogen replacement therapy on arthritis and bone mineral density in rats with collagen-induced arthritis. Bone 2001, 28:634-640.

9. Straub RH: The complex role of estrogens in inflammation. Endocr Rev 2007, 28:521-574.

10. Cutolo M, Capellino S, Straub RH: Oestrogens in rheumatic diseases: friend or foe? Rheumatology (Oxford) 2008, 47:iii2-iii5.

11. Walitt B, Pettinger M, Weinstein A, Katz J, Torner J, Wasko MC, Howard BV: Effects of postmenopausal hormone therapy on rheumatoid arthritis: the women's health initiative randomized controlled trials. Arthritis Rheum 2008, 59:302-310.

12. van den Brink HR, van Everdingen AA, van Wijk MJ, Jacobs JW, Bijlsma JW: Adjuvant oestrogen therapy does not improve disease activity in postmenopausal patients with rheumatoid arthritis. Ann Rheum Dis 1993, 52:862-865

13. Hall GM, Daniels M, Huskisson EC, Spector TD: A randomised controlled trial of the effect of hormone replacement therapy on disease activity in postmenopausal rheumatoid arthritis. Ann Rheum Dis 1994, 53:112-116.

14. D'Elia HF, Larsen A, Mattsson LA, Waltbrand E, Kvist G, Mellstrom D, Saxne T, Ohlsson C, Nordborg E, Carlsten H: Influence of hormone replacement therapy on disease progression and bone mineral density in rheumatoid arthritis. J Rheumatol 2003, 30:1456-1463.

15. Ishizuka M, Hatori M, Suzuki T, Miki Y, Darnel AD, Tazawa C, Sawai T, Uzuki M, Tanaka Y, Kokubun S, Sasano H: Sex steroid receptors in rheumatoid arthritis. Clin Sci 2004, 106:293-300.

16. Richmond RS, Carlson CS, Register TC, Shanker G, Loeser RF: Functional estrogen receptors in adult articular cartilage: estrogen replacement therapy increases chondrocyte synthesis of proteoglycans and insulin-like growth factor binding protein 2. Arthritis Rheum 2000, 43:2081-2090.

17. Erlandsson MC, Ohlsson C, Gustafsson JA, Carlsten H: Role of oestrogen receptors alpha and beta in immune organ development and in oestrogen-mediated effects on thymus. Immunology 2001, 103:17-25.

18. Kuiper GG, Carlsson B, Grandien K, Enmark E, Haggblad J, Nilsson S, Gustafsson JA: Comparison of the ligand binding specificity and transcript tissue distribution of estrogen receptors alpha and beta. Endocrinology 1997, 138:863-870.

19. Wong PK, Quinn JM, Sims NA, van Nieuwenhuijze A, Campbell IK, Wicks IP Interleukin-6 modulates production of T lymphocyte-derived cytokines in antigen-induced arthritis and drives inflammation-induced osteoclastogenesis. Arthritis Rheum 2006, 54:158-168.

20. Lawlor KE, Campbell IK, Metcalf D, O'Donnell K, van Nieuwenhuijze A, Roberts AW, Wicks IP: Critical role for granulocyte colony-stimulating factor in inflammatory arthritis. Proc Natl Acad Sci U S A 2004, 101:11398-11403.

21. Lawlor KE, Wong PK, Campbell IK, van Rooijen N, Wicks IP: Acute CD4+ T lymphocyte-dependent interleukin-1-driven arthritis selectively requires interleukin-2 and interleukin-4, joint macrophages, granulocyte-macrophage colony-stimulating factor, interleukin-6, and leukemia inhibitory factor. Arthritis Rheum 2005, 52:3749-3754.

22. Petrow PK, Thoss K, Katenkamp D, Brauer R: Adoptive transfer of susceptibility to antigen-induced arthritis into severe combined immunodeficient (SCID) mice: role of CD4+ and CD8+ T cells. Immunol Invest 1996, 25:341-353.

23. van den Berg WB, Joosten $L A$, van Lent PL: Murine antigen-induced arthritis. Methods Mol Med 2007, 136:243-253.

24. Dupont S, Krust A, Gansmuller A, Dierich A, Chambon P, Mark M: Effect of single and compound knockouts of estrogen receptors alpha (ERalpha) and beta (ERbeta) on mouse reproductive phenotypes. Development 2000, 127:4277-4291.

25. Börjesson AE, Lagerquist MK, Liu C, Shao R, Windahl SH, Karlsson C, Sjögren K, Movérare-Skrtic S, Antal MC, Krust A, Mohan S, Chambon P, Sävendahl L, Ohlsson C: The role of estrogen receptor alpha in growth plate cartilage for longitudinal bone growth. J Bone Miner Res 2010, $25: 2690-2700$ 
26. Ovchinnikov DA, Deng JM, Ogunrinu G, Behringer RR: Col2a1-directed expression of Cre recombinase in differentiating chondrocytes in transgenic mice. Genesis 2000, 26:145-146.

27. Lindberg MK, Weihua Z, Andersson N, Movérare S, Gao H, Vidal O, Erlandsson M, Windahl S, Andersson G, Lubahn DB, Carlsten H, Dahlman-Wright K, Gustafsson JA, Ohlsson C: Estrogen receptor specificity for the effects of estrogen in ovariectomized mice. J Endocrinol 2002, 174:167-178.

28. Offner $\mathrm{H}$, Adlard K, Zamora A, Vandenbark AA: Estrogen potentiates treatment with $\mathrm{T}$-cell receptor protein of female mice with experimental encephalomyelitis. J Clin Invest 2000, 105:1465-1472.

29. Engdahl C, Lindholm C, Stubelius A, Ohlsson C, Carlsten H, Lagerquist MK: Periarticular bone loss in antigen-induced arthritis. Arthritis Rheum 2013 65:2857-2865.

30. Itou T, Collins LV, Thoren FB, Dahlgren C, Karlsson A: Changes in activation states of murine polymorphonuclear leukocytes (PMN) during inflammation: a comparison of bone marrow and peritoneal exudate PMN. Clin Vaccine Immunol 2006, 13:575-583.

31. Dulos J, Vijn P, van Doorn C, Hofstra CL, Veening-Griffioen D, de Graaf J, Dijcks FA, Boots AM: Suppression of the inflammatory response in experimental arthritis is mediated via estrogen receptor alpha but not estrogen receptor beta. Arthritis Res Ther 2010, 12:R101.

32. Yang $\mathrm{YH}$, Ngo D, Jones M, Simpson E, Fritzemeier KH, Morand EF: Endogenous estrogen regulation of inflammatory arthritis and cytokine expression in male mice, predominantly via estrogen receptor alpha. Arthritis Rheum 2010, 62:1017-1025.

33. Follettie MT, Pinard M, Keith JC Jr, Wang L, Chelsky D, Hayward C, Kearney P, Thibault P, Paramithiotis E, Dorner AJ, Harris HA: Organ messenger ribonucleic acid and plasma proteome changes in the adjuvant-induced arthritis model: responses to disease induction and therapy with the estrogen receptor-beta selective agonist ERB-041. Endocrinology 2006, 147:714-723.

34. Hoffman-Goetz L: Effect of estradiol and exercise on lymphocyte proliferation responses in female mice. Physiol Behav 1999, 68:169-174.

35. Wang C, Dehghani B, Li Y, Kaler L, Vandenbark AA, Offner H: Oestrogen modulates experimental autoimmune encephalomyelitis and interleukin17 production via programmed death 1. Immunology 2009, 126:329-335.

36. Pohlers D, Nissler K, Frey O, Simon J, Petrow PK, Kinne RW, Brauer R: Anti-CD4 monoclonal antibody treatment in acute and early chronic antigen-induced arthritis: influence on T helper cell activation. Clin Exp Immunol 2004, 135:409-415.

37. Christodoulou C, Choy EH: Joint inflammation and cytokine inhibition in rheumatoid arthritis. Clin Exp Med 2006, 6:13-19.

38. Peck A, Mellins ED: Breaking old paradigms: Th17 cells in autoimmune arthritis. Clin Immunol 2009, 132:295-304.

39. Santos LL, Fan H, Hall P, Ngo D, Mackay CR, Fingerle-Rowson G, Bucala R, Hickey MJ, Morand EF: Macrophage migration inhibitory factor regulates neutrophil chemotactic responses in inflammatory arthritis in mice. Arthritis Rheum 2011, 63:960-970.

40. Rohner E, Matziolis G, Perka C, Fuchtmeier B, Gaber T, Burmester GR, Buttgereit $F$, Hoff P: Inflammatory synovial fluid microenvironment drives primary human chondrocytes to actively take part in inflammatory joint diseases. Immunol Res 2011, 52:169-175.

41. Romas E, Sims NA, Hards DK, Lindsay M, Quinn JW, Ryan PF, Dunstan CR, Martin TJ, Gillespie MT: Osteoprotegerin reduces osteoclast numbers and prevents bone erosion in collagen-induced arthritis. Am J Pathol 2002, 161:1419-1427.

42. Mulherin D, Fitzgerald O, Bresnihan B: Clinical improvement and radiological deterioration in rheumatoid arthritis: evidence that the pathogenesis of synovial inflammation and articular erosion may differ. Br J Rheumatol 1996, 35:1263-1268.

43. Fujishima S, Hoffman AR, Vu T, Kim KJ, Zheng H, Daniel D, Kim Y, Wallace EF, Larrick JW, Raffin TA: Regulation of neutrophil interleukin 8 gene expression and protein secretion by LPS, TNF-alpha, and IL-1 beta. J Cell Physiol 1993, 154:478-485.

44. Kinne RW, Stuhlmuller B, Burmester GR: Cells of the synovium in rheumatoid arthritis. Macrophages. Arthritis Res Ther 2007, 9:224.

45. Ito I, Hayashi T, Yamada K, Kuzuya M, Naito M, Iguchi A: Physiological concentration of estradiol inhibits polymorphonuclear leukocyte chemotaxis via a receptor mediated system. Life Sci 1995, 56:2247-2253.

46. Miller MD, Krangel MS: Biology and biochemistry of the chemokines: a family of chemotactic and inflammatory cytokines. Crit Rev Immunol 1992, 12:17-46.

47. Bacon KB, Oppenheim JJ: Chemokines in disease models and pathogenesis. Cytokine Growth Factor Rev 1998, 9:167-173.
48. Wenke AK, Niebler S, Grassel S, Bosserhoff AK: The transcription factor AP-2varepsilon regulates CXCL1 during cartilage development and in osteoarthritis. Osteoarthritis Cartilage 2011, 19:206-212.

49. Grespan R, Fukada SY, Lemos HP, Vieira SM, Napimoga MH, Teixeira MM, Fraser AR, Liew FY, McInnes IB, Cunha FQ: CXCR2-specific chemokines mediate leukotriene B4-dependent recruitment of neutrophils to inflamed joints in mice with antigen-induced arthritis. Arthritis Rheum 2008, 58:2030-2040.

50. Merck E, Gaillard C, Scuiller M, Scapini P, Cassatella MA, Trinchieri G, Bates EE: Ligation of the FcR gamma chain-associated human osteoclast-associated receptor enhances the proinflammatory responses of human monocytes and neutrophils. J Immunol 2006, 176:3149-3156.

doi:10.1186/ar4612

Cite this article as: Engdahl et al:: The role of total and cartilage-specific estrogen receptor alpha expression for the ameliorating effect of estrogen treatment on arthritis. Arthritis Research \& Therapy 2014 16:R150.

\section{Submit your next manuscript to BioMed Central and take full advantage of:}

- Convenient online submission

- Thorough peer review

- No space constraints or color figure charges

- Immediate publication on acceptance

- Inclusion in PubMed, CAS, Scopus and Google Scholar

- Research which is freely available for redistribution
Ciomed Central 